\title{
Bacillus cereus Nhe is a pore-forming toxin with
structural and functional properties similar to the
ClyA (HlyE, SheA) family of haemolysins, able to
induce osmotic lysis in epithelia \\ Correspondence \\ Simon P. Hardy \\ simon.hardy@veths.no \\ Received 27 October 2007 \\ Revised 13 December 2007 \\ Accepted 13 December 2007

\author{
Annette Fagerlund, Toril Lindbäck, Anne K. Storset, Per Einar Granum \\ and Simon P. Hardy
}
Department of Food Safety and Infection Biology, Norwegian School of Veterinary Science, PO Box 8146 Dep., N-0033 Oslo, Norway

\begin{abstract}
The mechanism by which Bacillus cereus causes diarrhoea is unknown. Three putative enterotoxins have been proposed, haemolysin $\mathrm{BL}(\mathrm{Hbl})$, cytotoxin $\mathrm{K}$ and non-haemolytic Nhe against epithelia is dependent on all three components. However, little is known of the mechanism of cytotoxicity. Markers of plasma membrane disruption, namely propidium iodide uptake, loss of cellular ATP and release of lactate dehydrogenase (LDH), were observed in epithelia exposed to Nhe from culture supernatants of $B$. cereus, but not in those exposed to supernatants from a mutant strain lacking NheB and NheC. Consistent with an exogenous cause of membrane damage, purified Nhe components combined to form large conductance pores in size caused by Nhe indicate that epithelia lyse following osmotic swelling. Nhe and Hbl show sequence homology, and $\mathrm{Hbl}$ component $\mathrm{B}$ has remarkable structural similarities to cytolysin $\mathrm{A}$ hydrophobic $\beta$-hairpin. Correspondingly, we show that Nhe has haemolytic activity against erythrocytes from a variety of species. We propose that the common structural and functional properties indicate that the $\mathrm{Hbl} / \mathrm{Nhe}$ and ClyA families of toxins constitute a superfamily of pore-forming cytotoxins.
\end{abstract} enterotoxin (Nhe). Both $\mathrm{Hbl}$ and $\mathrm{Nhe}$ are three-component cytotoxins and maximal cytotoxicity of planar lipid bilayers. The inhibition of LDH release by osmotic protectants and the increase in cell (ClyA), with both structures possessing an $\alpha$-helix bundle and a unique subdomain containing a
}

\section{INTRODUCTION}

Bacillus cereus is a worldwide cause of food-associated illness in man. Although B. cereus was shown to cause enteritis in humans over 50 years ago (Hauge, 1955), the cellular mechanism of diarrhoea and identity of the responsible enterotoxin(s) remain unknown. Three putative enterotoxins of $B$. cereus have been proposed: haemolysin $\mathrm{BL}(\mathrm{Hbl})$, non-haemolytic enterotoxin (Nhe) and cytotoxin $\mathrm{K}$ (CytK), all of which are cytotoxic to epithelia in vitro. CytK is a haemolytic pore-forming toxin with homology to the $\beta$-barrel pore-forming toxins, including staphylococcal $\alpha$-haemolysin (Hardy et al., 2001a; Lund et al., 2000). Hbl and Nhe are tripartite toxins, in which all three components are necessary for maximal cytotoxic activity (Beecher \& Macmillan, 1991; Lindbäck et al., 2004). Both are encoded by three genes cotranscribed as operons in which hblCDA encodes $\mathrm{Hbl}$ components $\mathrm{L}_{2}, \mathrm{~L}_{1}$ and $\mathrm{B}$, and nheABC encodes NheA,

Abbreviations: EC buffer, extracellular bathing solution; LDH, lactate dehydrogenase; $\mathrm{Pl}$, propidium iodide.
NheB and NheC. Sequence homology is apparent both between the three components in each complex and between the proteins of Nhe and $\mathrm{Hbl}$ (Granum et al., 1999; Ryan et al., 1997; Table 1). With no sequence homology to other toxins, Nhe and Hbl have remained unclassified as toxins.

$\mathrm{Hbl}$ has been shown to possess a variety of biological effects, including haemolytic, dermonecrotic and vascular permeability activities and, significantly, possesses enterotoxigenic ability, as indicated by fluid accumulation in rabbit ligated ileal loops (reviewed by Schoeni \& Wong, 2005). Nhe was identified in B. cereus following a large food-poisoning outbreak in Norway (Lund \& Granum, 1996). The recovered isolate, NVH 0075/95, lacked both $h b l$ and $c y t K$ (Ehling-Schulz et al., 2005) but was still cytotoxic, thus permitting the discovery of Nhe. The initial study indicated that the toxin was non-haemolytic.

Although the toxin profile may differ between strains, it appears that Nhe is a dominant cytotoxic component of $B$. cereus. In a study of over 100 B. cereus strains, cytotoxicity correlated well with the amount of Nhe produced but 
Table 1. Identity table giving the values for percentage identity between ClyA from E. coli K-12 and the mature proteins of the $\mathrm{Hbl}$ and Nhe complexes from B. cereus ATCC 14579, obtained using Smith-Waterman global alignments and the Blosum 50 similarity matrix

\begin{tabular}{|c|c|c|c|c|c|c|}
\hline & $\mathrm{Hbl} \mathrm{L_{2 }}$ & Hbl L $L_{1}$ & Hbl B & NheA & NheB & NheC \\
\hline ClyA & $18 \%$ & $20 \%$ & $20 \%$ & $18 \%$ & $19 \%$ & $20 \%$ \\
\hline $\mathrm{Hbl} \mathrm{L}_{2}$ & & $18 \%$ & $23 \%$ & $23 \%$ & $21 \%$ & $19 \%$ \\
\hline $\mathrm{Hbl} \mathrm{L}$ & & & $25 \%$ & $18 \%$ & $40 \%$ & $32 \%$ \\
\hline $\mathrm{Hbl} \mathrm{B}$ & & & & $20 \%$ & $27 \%$ & $25 \%$ \\
\hline NheA & & & & & $22 \%$ & $22 \%$ \\
\hline NheB & & & & & & $44 \%$ \\
\hline
\end{tabular}

poorly with the concentration of $\mathrm{Hbl}$ (Moravek et al., 2006). The same group (Dietrich et al., 2005) found that $\mathrm{mAb} 1 \mathrm{E} 11$ raised against $\mathrm{NheB}$ prevented cytotoxicity in 20 out of 20 strains of $B$. cereus isolated from food. In a study of Bacillus thuringiensis strain $407 \mathrm{Cry}^{-}$(indistinguishable from B. cereus), culture supernatants from $h b l$ and $c y t K$ deletion mutants showed no impairment in cytotoxicity towards HeLa and Caco-2 cells (Ramarao \& Lereclus, 2006), implying that Nhe was the major virulence factor.

Previously, we have shown that maximal cytotoxic activity of Nhe against Vero cell epithelia is dependent on all three Nhe components (Lindbäck et al., 2004). Cytotoxicity was quantified as inhibition of protein synthesis based on the impairment of leucine uptake (Lindbäck \& Granum, 2006). With rapidly cytotoxic proteins this assay may be more a measure of uptake of radiolabelled leucine across the epithelial plasma membrane than of protein synthesis per se. Thus, following microscopic observations of increasing size of blebs in cells in response to $B$. cereus culture supernatants, we chose to investigate the nature of the plasma membrane damage using more direct markers. Using the B. cereus strain NVH $0075 / 95$ and an isogenic nheBC mutant expressing only NheA, we show that Nhe acts as a pore-forming toxin to induce cell lysis. Additionally, we show structural and functional correlates between Nhe, $\mathrm{Hbl}$ and the pore-forming haemolysin cytolysin A (ClyA) from Gram-negative enteric bacteria.

\section{METHODS}

Cells, buffers and antibodies. Monolayers of Vero monkey kidney epithelia and human intestinal Caco-2 cells were grown under standard tissue culture conditions using minimal essential medium (MEM) and RPMI 1640 respectively, with $5 \%(\mathrm{v} / \mathrm{v})$ fetal calf serum. MEM was supplemented with penicillin $\left(100 \mathrm{U} \mathrm{ml}^{-1}\right)$ and streptomycin $\left(0.1 \mathrm{mg} \mathrm{ml}^{-1}\right)$, and RPMI 1640 with gentamicin $\left(0.05 \mathrm{mg} \mathrm{ml}^{-1}\right)$ and glutamine $(2.4 \mathrm{mM})$. Cells were subcultured from $25 \mathrm{ml}$ flasks when confluent using cell scrapers and tritruation, except for flow cytometric experiments, in which EDTA was used to detach cells from the flasks. All experiments on cultured cells were carried out in extracellular bathing solution (referred to as EC buffer) containing $\mathrm{NaCl}(135 \mathrm{mM})$, HEPES (15 mM), $\mathrm{MgCl}_{2}$ (1 mM), $\mathrm{CaCl}_{2}$ $(1 \mathrm{mM})$ and glucose $(10 \mathrm{mM})$, adjusted to $\mathrm{pH} 7.0-7.1$ with Tris. The non-neutralizing $\mathrm{mAbs} 1 \mathrm{~A} 8$, raised against NheA (Dietrich et al.,
2005), and 1C2, raised against NheB (Dietrich et al., 1999), were used for immunoblotting. mAb $1 \mathrm{E} 11$, raised against $\mathrm{NheB}$, is able to neutralize the cytotoxic activity of Nhe, as described by Dietrich et al. (2005).

Creation of the nheBC mutant. A truncation mutant in $n$ heB of $B$. cereus NVH 0075/95, isolated from an outbreak of food poisoning in Norway (Lund \& Granum, 1996), was created fortuitously whilst deleting nheC. Thus, the method described here is that devised to delete nhe $C$ alone. Subregions of the nheB and nheC genes were amplified by PCR using primer pairs GCGAAGCAATGGTTAGATGTA and CACAACTGAACAGGAGCTTC, and GCGATTGATCAAAAGGATAG and AAAAATAAACAGCAGAACTAGTCCAC, respectively. PCR was carried out for 30 cycles using an annealing temperature of $50{ }^{\circ} \mathrm{C}$. PCR products of $n h e B$ and $n h e C$ were cloned into pCR T7/NT-TOPO and pCR 2.1-TOPO (Invitrogen), respectively, and transformed into Escherichia coli One Shot TOP10 (Invitrogen). nheC was excised from pCR2.1-TOPO using EcoRI, and ligated into the EcoRI site of pMAD (Arnaud et al., 2004). nheB was excised from pCRT7/NT-TOPO using BamHI and HindIII, and ligated into the BamHI site of pMAD together with the spectinomycin resistance cassette from pDG1726 (Guérout-Fleury et al., 1995) digested with BamHI and HindIII, producing pMAD $\Delta$ neC. DNA sequencing confirmed that the plasmid did not contain any mutations in $n$ heB introduced during PCR. This plasmid was electroporated into B. cereus NVH 0075/95 (Masson et al., 1989), and transformants were subjected to allelic exchange as described elsewhere (Arnaud et al., 2004). DNA sequencing of the obtained double-crossover mutant confirmed the deletion of $n h e C$, while a single-base deletion of the 967th base (guanosine) was introduced into nheB. This deletion is likely to result in a truncated form of NheB due to a frameshift, as the last 80 amino acids were absent.

Crude toxin preparation (culture supernatants). B. cereus NVH 0075/95 and the isogenic nheBC mutant were grown in a modified casamino acids/glucose/yeast extract (CGY) broth as defined by Lund \& Granum (1997), but with the $1 \%$ glucose replaced by $1 \%$ sucrose (Ouhib et al., 2006). A $1 \%$ inoculum of an overnight culture was incubated in $50 \mathrm{ml}$ CGY (in a $250 \mathrm{ml}$ flask) at $32{ }^{\circ} \mathrm{C}$ shaken at 100 r.p.m. for $5 \mathrm{~h}$ (early stationary phase). The supernatant was centrifuged and filtered through a $0.2 \mu \mathrm{m}$ pore-size membrane filter and stored in aliquots at $-80{ }^{\circ} \mathrm{C}$.

Purification of Nhe components. NheA and NheB were purified from 5 h culture supernatants of B. cereus NVH0075/95 as described previously (Lindbäck et al., 2004), with the following modifications: 11 CGY was used to culture the organism rather than 31 , and the proteins were precipitated with $50 \%(\mathrm{w} / \mathrm{v})$ ammonium sulphate. NheB was analysed by DEAE chromatography at $\mathrm{pH} 8$. NheC was purified as a recombinant hexahistidine-tagged protein expressed in E. coli (Lindbäck et al., 2004). Protein concentrations were estimated using the absorbance method of Whitaker \& Granum (1980), in conjunction with visual assessment of titrations of the purified Nhe components from band densities on SDS-PAGE gels.

SDS-PAGE and immunoblotting. PAGE and Western immunoblotting were carried out as described previously (Lindbäck et al., 2004), using mAbs 1A8 (Dietrich et al., 2005) and 1C2 (Dietrich et al., 1999). Biotin-conjugated goat anti-mouse antibody was used as a secondary antibody $(1: 1000)$. A complex of streptavidin and biotinylated alkaline phosphatase was used at a dilution of $1: 3000$, prior to developing with nitro blue tetrazolium/5-bromo-4-chloro-3indolyl phosphate.

Propidium iodide (PI) uptake by Caco-2 and Vero epithelia. For microscopy studies, Vero and Caco-2 cells were grown on coverslips in 6-well microplates and tested after 3 days, having reached $80-90 \%$ 
confluence. Cells were washed with $1 \mathrm{ml} \mathrm{EC} \mathrm{buffer}$ solution and incubated with dilutions of culture supernatants. Cells were incubated in $5 \% \mathrm{CO}_{2}$ for up to $60 \mathrm{~min}$. At various time points the medium was replaced with fresh medium containing $5 \mu \mathrm{g} \mathrm{PI} \mathrm{ml}{ }^{-1}(7.5 \mu \mathrm{M})$ and the coverslips were removed for examination by epifluorescence microscopy at the end of the experiment. A halogen light source was set to $570 / 620 \mathrm{~nm}$ excitation/emission wavelengths. Time-course experiments of PI fluorescence in epithelia were performed using a Wallac Victor ${ }^{3}$ fluorimeter (Perkin Elmer). Caco-2 cells were cultured in 24-well microplates and tested 10-14 days after seeding, while Vero cells were tested 2-4 days after seeding. After equilibrating cells in EC buffer for 10-15 min, microplates were transferred to the heated chamber of the Victor ${ }^{3}$ (held at $37^{\circ} \mathrm{C}$ ), the bathing solution (buffer) was replaced with one containing PI $\left(5 \mu \mathrm{g} \mathrm{ml}^{-1}\right)$, and dilutions of culture supernatant were added. Microplates were 'bottom read' to record fluorescence in cells attached to the base of the well using excitation/emission wavelengths of 575/595 nm. Wells were read at $1 \mathrm{~min}$ intervals for $1 \mathrm{~s}$ duration. Saponin $(0.0025 \%$, w/v, in EC buffer) was used as a positive control to monitor fluorescence. Results are shown without subtraction of background fluorescence; hence baseline values increased with increasing volumes of culture supernatant. Note also that since divalent cations quench fluorescence (Gibbons et al., 2001), absolute values are not of any significance. This was particularly noticeable in calcium- and magnesium-free buffer, which gave higher basal readings than the standard EC buffer. The rate of PI uptake was expressed as the mean change in fluorescence per minute measured over a $10-15$ min period, starting with the lowest reading obtained before fluorescence increased.

Epithelial ATP content and lactate dehydrogenase (LDH) release. Cell culture medium was replaced with EC buffer and allowed to equilibrate for at least $10 \mathrm{~min}$ before exposure to culture supernatant in $1 \mathrm{ml}$ final volumes. For measurement of LDH release following exposure of Vero and Caco-2 monolayers to the culture supernatant, duplicate samples of EC buffer were removed at various intervals and briefly centrifuged before analysis on an ADVIA 1650 autoanalyser (Beyer). Total cell monolayer ATP was measured by replacing the entire cell bathing solution after exposure to toxin at various time points with $1 \mathrm{ml}$ buffer containing $1 \%(\mathrm{v} / \mathrm{v})$ Triton $\mathrm{X}$ 100. After $10 \mathrm{~min}$ incubation, duplicate $100 \mu \mathrm{l}$ samples of the lysed cell suspensions were diluted $1: 100$ before mixing with $100 \mu \mathrm{l}$ luciferase reaction buffer (BacTiter-Glo Microbial Cell Viability Assay, Promega) for $5 \mathrm{~min}$ and measurement in a Glomax 20/20 luminometer (Promega). Results were expressed in the original arbitrary lux units. Total monolayer LDH was measured at the end of the experiment after lysis with $1 \mathrm{ml} 1.0 \%$ Triton X-100 in EC buffer.

For osmotic protection of LDH release, glucose (30 mM, hydrodynamic radius $0.36 \mathrm{~nm})$, PEG $400(30 \mathrm{mM}, 0.68 \mathrm{~nm})$, PEG 1000 $(28 \mathrm{mM}, 0.94 \mathrm{~nm})$ and PEG $8000(10 \mathrm{mM}, 3.78 \mathrm{~nm})$ were dissolved in EC buffer. Osmotic protectants were added in reducing molarities so as to offset the increase in osmolarity in the final bathing solutions. Cells were preincubated for $10-15 \mathrm{~min}$ in the prewarmed solutions containing PEG before addition of $20 \mu \mathrm{m} \mathrm{m}^{-1}$ culture supernatants. Hydrodynamic radii were taken from Scherrer \& Gerhardt (1971) and Planchot et al. (2000).

Planar lipid bilayer experiments. Investigation of the ability of purified Nhe to form single channel-like pores in synthetic phosphatidylethanolamine-phosphatidylserine (PE-PS) lipid bilayers was carried out as described previously (Hardy et al., 2001b). Purified Nhe components in $0.1 \mathrm{M} \mathrm{NaCl}$ phosphate buffer in a ratio of $1: 1: 0.3 \mathrm{NheA}$ : NheB: NheC, using approximately $40 \mathrm{ng}$ NheA, were premixed before addition to the earthed bathing solution. Recordings were filtered at $500 \mathrm{~Hz}$ and acquired to computer disc using a Digidata $1200 \mathrm{AD}$ converter at $5 \mathrm{kHz}$, and analysed off-line.
Single-channel conductances were estimated individually using Win EDR (Strathclyde Electrophysiology Software).

Flow cytometric measurement of cell size and PI uptake. Vero cells were detached from culture flasks by standard protocols with trypsin/EDTA inactivated by exposure to $10 \%$ fetal calf serum in the growth medium. Prior to exposure to the toxin the cells were equilibrated at $37{ }^{\circ} \mathrm{C}$ in EC buffer with $5 \mu \mathrm{g} \mathrm{PI} \mathrm{ml}{ }^{-1}$ for $10 \mathrm{~min}$. Vero cell suspensions were assayed for forward light scatter and PI uptake using a FACSCalibur flow cytometer (Becton Dickinson Biosciences) with a $488 \mathrm{~nm}$ wavelength argon laser with linear amplification of the forward- and side-scatter light signals and logarithmic amplification of the fluorescence signals of each cell. Data were collected from 10000 cells per time point. Cells were held at room temperature for the duration of the experiment $(15 \mathrm{~min})$. Analysis was carried out using CellQuest Pro software (Becton Dickinson Biosciences). Following normalization of cell size at time zero, statistical comparison between the effect of $20 \mu \mathrm{ml}^{-1}$ culture supernatants of NVH 0075/95 and the nheBC mutant on cell size (mean forward scatter value) was carried out on the area under the curve for the two samples using the Mann-Whitney test.

Haemolysis assays. Blood cells from different species were washed three to six times in PBS. Purified Nhe proteins were used at a ratio of 6:6:1 NheA: NheB: NheC, using approximately $100 \mathrm{ng} \mathrm{NheA} \mathrm{ml}^{-1}$. Volumes of culture supernatants were incubated with $2 \%(\mathrm{v} / \mathrm{v})$ bovine blood, and freshly combined Nhe components were incubated with blood samples from different species diluted to concentrations obtaining the same $\mathrm{OD}_{630}$ as $1.5 \%$ human blood. After incubation at $37{ }^{\circ} \mathrm{C}$ for $60 \mathrm{~min}$ on a roller incubator, samples were centrifuged and haemolysis was determined from the $A_{540}$ of the supernatants. The percentage of haemolysis was calculated by comparing the $A_{540}$ of the samples with positive (100\% lysis by $1 \%$ Triton X-100) and negative controls. All experiments were performed at least twice.

\section{RESULTS}

\section{Characterization of the nheBC double mutant}

During attempts to create an isogenic nheC deletion mutant in B. cereus strain NVH 0075/95 we were only able to obtain mutants which contained an additional frameshift mutation in $n h e B$, resulting in an $n h e B C$ double mutant. Immunoblotting analysis of supernatants from $5 \mathrm{~h}$ cultures failed to detect NheB in the $\triangle n h e B C$ strain, in contrast to the wild-type strain NVH 0075/95 (Fig. 1). Growth curves were indistinguishable between the two strains, each yielding $10^{8}$ c.f.u. $\mathrm{ml}^{-1}$ after $5 \mathrm{~h}$ incubation at $32{ }^{\circ} \mathrm{C}$.

\section{Microscopic cytotoxicity of Nhe on Caco-2 and Vero cells}

We examined the effect of Nhe on Caco-2 cell monolayers by microscopy. Cells often developed blebs at the plasma membrane, typically a single bleb that increased in size with time and eventually burst. Fluorescent dyes such as PI are excluded from cells with intact plasma membranes but will enter cells if pores of sufficient size are created in the plasma membrane. Upon intercalation with nucleic acid these dyes undergo Stokes shift and can be detected by their fluorescence. Microscopic examination of both Vero 
Anti-NheA

Anti-NheB

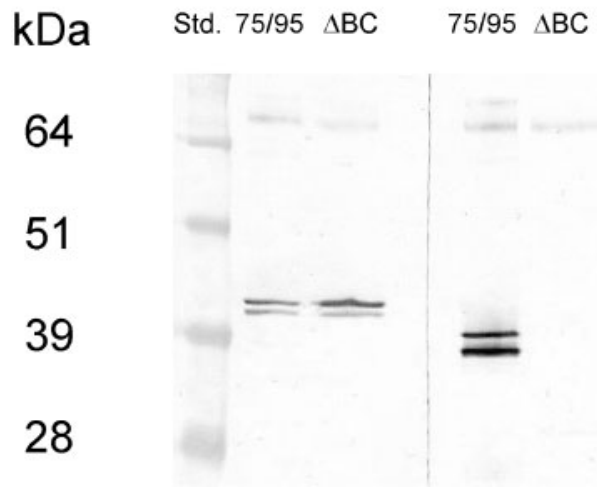

Fig. 1. Nhe content and haemolytic activity in $B$. cereus culture supernatants. Western immunoblot of culture supernatants from $B$. cereus NVH 0075/95 (75/95) and the nheBC mutant $(\triangle \mathrm{BC})$ probed with antisera against $\mathrm{NheA}$ and $\mathrm{NheB}$. The size marker (Std.) used was SeeBlue Plus2 Pre-stained Standard (Invitrogen). Both proteins yield two bands as a result of minor degradation, as observed previously (Lund \& Granum, 1996, 1997).

and Caco-2 cells exposed to NVH 0075/95 supernatant demonstrated uptake of PI, detectable down to $6 \mu \mathrm{ml}^{-1}$. Photomicrographic images of Vero cells exposed to NVH 0075/95 supernatant, co-illuminated with both epifluorescent and phase-contrast illumination, showed development of clear blebs (i.e. free from organelles), which subsequently burst, leaving a granular appearance of what is likely to be the cytoplasm surrounding a red fluorescent nucleus (Fig. 2a). In contrast, cells exposed to up to $50 \mu \mathrm{l}$ $\mathrm{ml}^{-1}$ supernatant from the nheBC mutant for up to $60 \mathrm{~min}$ excluded PI and appeared morphologically indistinguishable from cells exposed to culture medium alone (Fig. 2b).

\section{Nhe induces PI uptake in Caco-2 cell monolayers}

To quantify the rate of PI uptake in real-time we developed a fluorometric assay using epithelial monolayers grown in 24-well microplates. Fig. 3(a) shows the increase in PI fluorescence from Caco-2 cells over $20 \mathrm{~min}$ following exposure to NVH 0075/95 culture supernatant, and the rate of propidium fluorescence increasing in a dosedependent manner (Fig. 3b). In contrast, Caco-2 cells exposed to up to $50 \mu \mathrm{l} \mathrm{ml}^{-1}$ culture supernatant from the nheBC mutant exhibited no increase in fluorescence (Fig. 3a). PI uptake in Caco-2 cells exposed to $20 \mu \mathrm{l}$ $\mathrm{ml}^{-1} \mathrm{NVH}$ 0075/95 culture supernatant was not dependent on extracellular divalent cations, since cells bathed in extracellular buffer with no added calcium or magnesium also exhibited prompt increases in PI fluorescence (data not shown). The increase in PI fluorescence was abolished in cells exposed to toxin that had been held at $60{ }^{\circ} \mathrm{C}$ for 20 min (data not shown) or preincubated with the neutralizing $\mathrm{mAb}$ against NheB, 1E11 (Fig. 3a). (a)

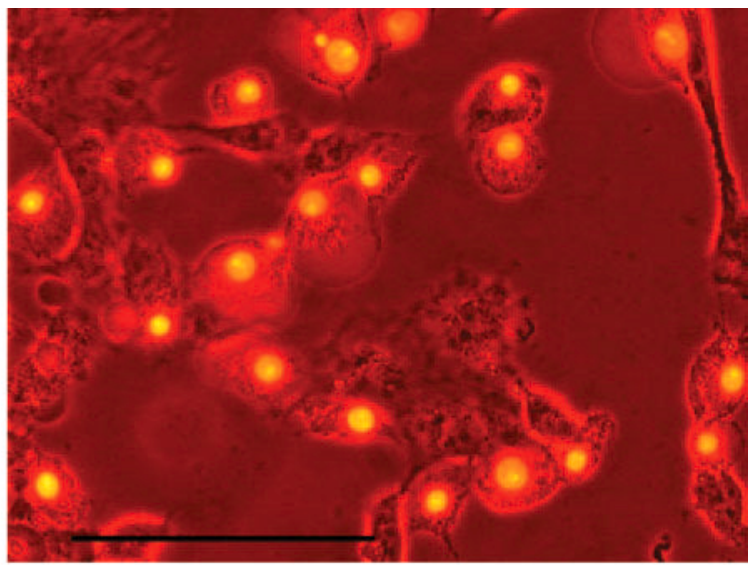

(b)

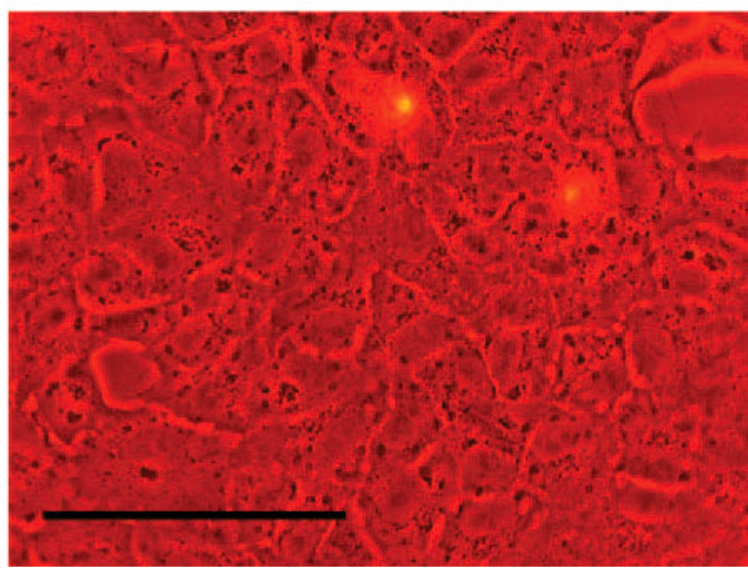

Fig. 2. Cytotoxicity of $B$. cereus NVH 0075/95 culture supernatant to Vero cells. (a) Photomicrograph taken $30 \mathrm{~min}$ after addition of $12.5 \mu \mathrm{m} \mathrm{ml}^{-1} \mathrm{NVH}$ 0075/95 culture supernatant with dual phase-contrast and epifluorescent illumination in a bathing solution containing $5 \mu \mathrm{g} \mathrm{Pl} \mathrm{ml}^{-1}$. Note the numerous bright nuclei and clear swollen extrusions. (b) Vero cells exposed to $12.5 \mu \mathrm{m} \mathrm{ml}^{-1}$ culture supernatant from the nheBC mutant for $60 \mathrm{~min}$. Bars, $0.1 \mathrm{~mm}$.

\section{PI uptake induced by Nhe is not blocked by glycine or induced by extracellular purinergic (ATP) activation in Caco-2 epithelia}

PI uptake has been demonstrated in cells exposed to maitotoxin (Schilling et al., 1999), cells that have been metabolically poisoned and in macrophages undergoing pyroptosis due to salmonellae (Fink \& Cookson, 2006). In all three situations, PI uptake has been shown to be inhibited by $5 \mathrm{mM}$ glycine but not by L-leucine. To determine whether the plasma membrane permeability to PI induced by Nhe was related to the activation of these undefined endogenous pores we exposed Caco-2 epithelia to NVH $0075 / 95$ culture supernatants $\left(20 \mu \mathrm{ml}^{-1}\right)$ in the presence of $5 \mathrm{mM}$ glycine and leucine. PI uptake was unaffected by either amino acid (data not shown).

Purinergic activation of certain cell types is also able to cause PI uptake (Pelegrin \& Surprenant, 2006). However, 

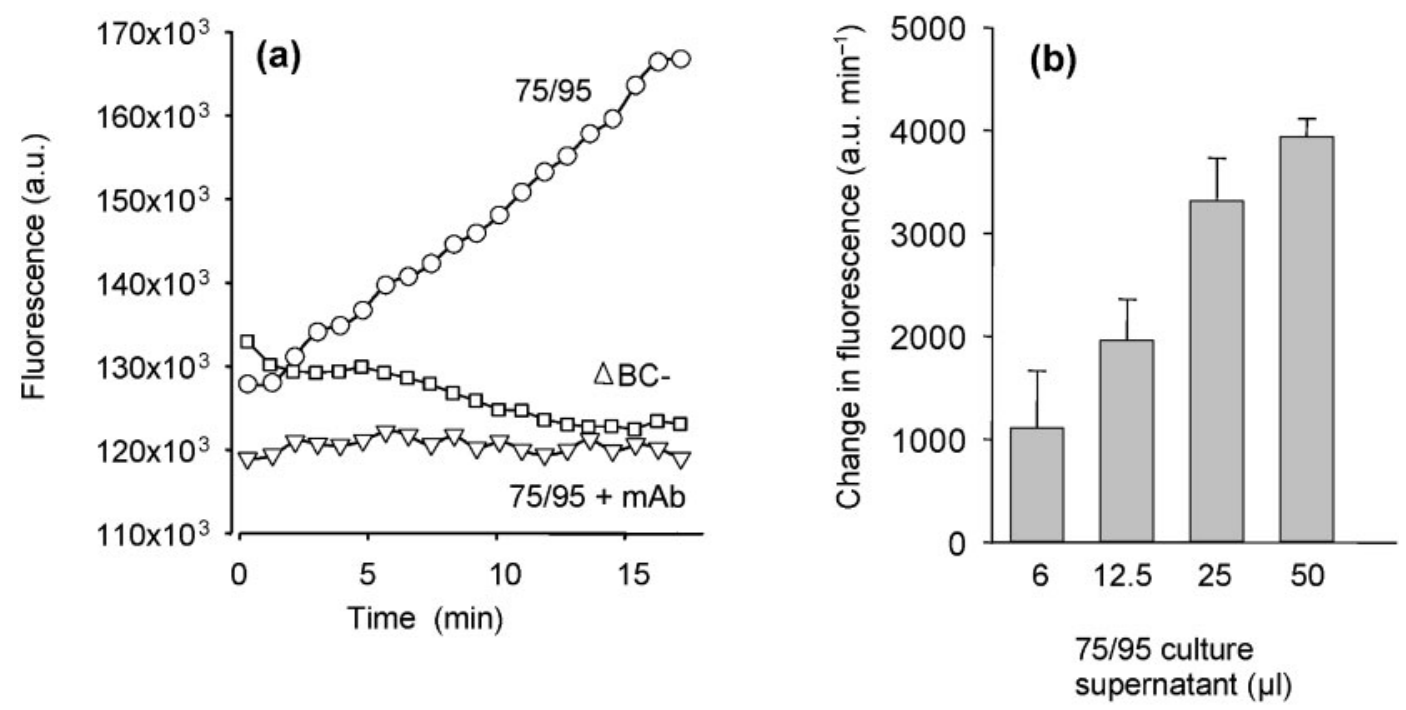

Fig. 3. $\mathrm{PI}$ uptake in Caco-2 epithelia is dependent on all three Nhe proteins. (a) Time-course of propidium fluorescence in Caco-2 epithelia exposed to $20 \mu \mathrm{ml}^{-1}$ culture supernatant from NVH 0075/95 (75/95; $\left.\bigcirc\right)$. The fluorescence increase

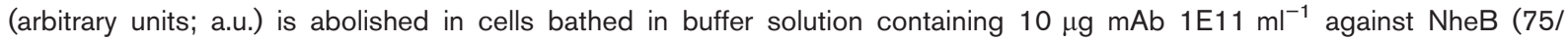
$95+\mathrm{mAb} ; \nabla)$. Pl fluorescence did not increase when $20 \mu \mathrm{ml}^{-1}$ culture supernatant from the nheBC mutant $(\Delta \mathrm{BC}-; \square)$ was added. Results are representative of six to eight wells for both $75 / 95$ and $\triangle B C-$, and of three wells for $75 / 95+m A b$. (b) Concentration-dependent increase in fluorescence following exposure to NVH 0075/95 culture supernatants. Fluorescence is expressed as change in fluorescence measured (mean \pm SE, $n=6-8$ wells for each dataset).

PI uptake in Caco-2 cells was not detected following exposure of the cells to $0.3 \mathrm{M}$ ATP (data not shown). Thus, PI fluorescence in Caco-2 cells exposed to Nhe in B. cereus culture supernatants is not due to the undefined endogenous death pore activated by pyroptosis or purinergic activation by ATP.

\section{Purified Nhe forms pores in planar lipid bilayers}

The above data are consistent with increases in plasma membrane permeability induced by Nhe rather than activation of the endogenous channels linked with the inflammasome and cell death. To support this distinction, we added purified Nhe components to planar synthetic lipid bilayer membranes, which by definition will lack endogenous channels or receptors. Fig. 4(a) (upper trace) shows the prompt step-like increases in membrane conductance observed following addition of the three purified Nhe components. Typically, multiple levels of current were observed in which openings and closings of the channels could be seen before the current exceeded the headstage or the bilayer was disrupted. The time taken for channels to insert in the bilayer was $1.5 \pm 0.2 \mathrm{~min}$ (mean \pm SE, $n=14)$. The specificity of the pore formation being due to Nhe rather than co-purifying contaminants was confirmed by the prevention of the appearance of channels in the bilayer by addition of the neutralizing antibody against NheB (1E11) to the bathing solution prior to the addition of Nhe, at least within a period up to 15 $17 \mathrm{~min}$ (Fig. 4a, lower trace). In contrast, addition of non-specific IgG (affinity-purified goat anti-rabbit antibody) did not significantly increase the time taken for channels to appear $(2.3 \pm 0.6 \mathrm{~min}$, mean $\pm \mathrm{SE}, n=7$, $P>0.05$, unpaired $t$ test). The range of channel conductances in $0.1 \mathrm{M} \mathrm{NaCl}$ is shown in Fig. 4(b). Channels of 200-700 pS dominated (mean $400 \pm 58 \mathrm{pS}$ in $0.1 \mathrm{M} \mathrm{NaCl}$ ), but both lower and higher conductances were observed. The pores were able to conduct both cations and anions; however, replacement of sodium with a larger cation $(\mathrm{N}-$ methyl-D-glucamine) reduced the mean conductance to $235 \pm 26 \mathrm{pS}$ in $0.1 \mathrm{M}$ sodium gluconate, whereas replacement of chloride ions with the larger gluconate ion had less effect, yielding channels with mean conductance of $400 \pm 33 \mathrm{pS}$ ( $0.1 \mathrm{M}$ sodium gluconate). Thus, cations appear to permeate preferentially with respect to anions in the large conductance channels formed by Nhe in planar lipid bilayers.

\section{Nhe causes ATP and LDH release from Caco-2 and Vero cell monolayers}

The rapidity of action and the size of the putative pores in cell membranes were studied by measuring both cellular ATP and released LDH in Caco- 2 monolayers following exposure to culture supernatants. Fig. 5(a) shows the prompt fall in intracellular ATP, in which over $90 \%$ of ATP was lost after $5 \mathrm{~min}$, in Caco-2 monolayers exposed to $20 \mu \mathrm{l} \mathrm{ml}{ }^{-1} \mathrm{NVH} \quad 0075 / 95$ supernatant. In contrast, supernatant from the nheBC mutant had no significant effect on ATP levels in the cell monolayers. An indication 
(a)
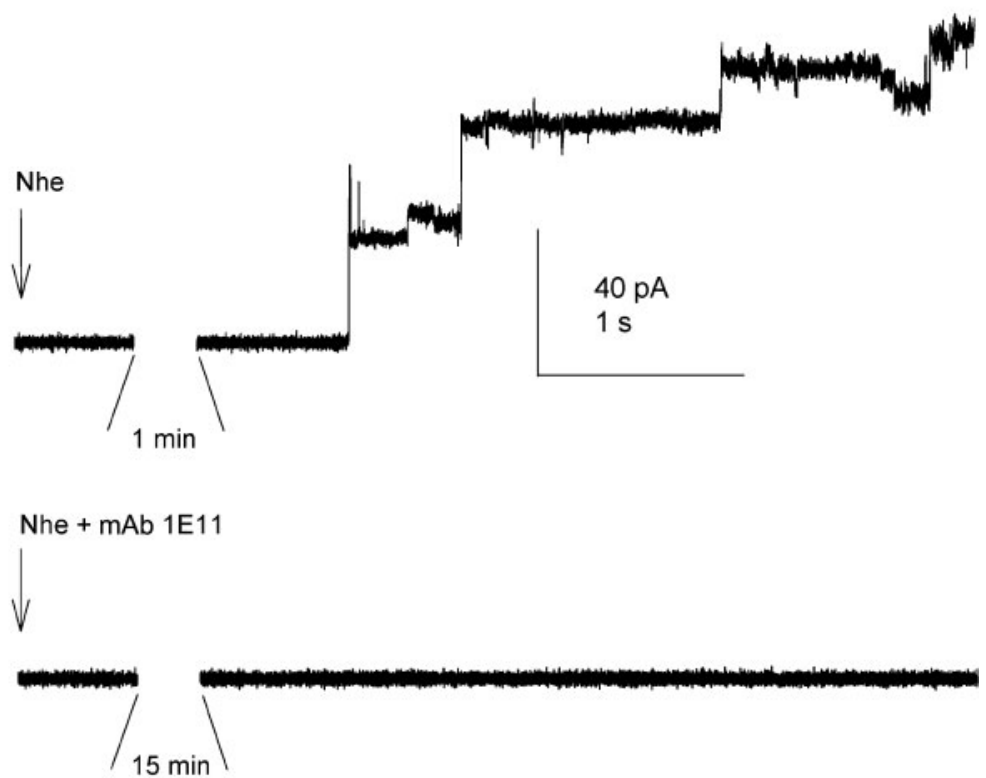

Fig. 4. Nhe forms pores in planar lipid bilayers. (a) Representative recording of current flow across lipid bilayer induced by Nhe and the effect of a mAb against NheB. Upper trace, channel-like step increases in current occurring approximately 1 min after addition of purified Nhe proteins to the bathing solution (taken from one of 14 bilayers); lower trace, addition of $10 \mu \mathrm{g} \mathrm{mAb} 1 \mathrm{E} 11 \mathrm{ml}^{-1}$ to the bathing solution prior to the addition of Nhe prevented any channel insertions (one of three bilayers). Bilayers were bathed in $0.1 \mathrm{M} \mathrm{NaCl}$, $5 \mathrm{mM}$ HEPES, $\mathrm{pH} 7.0$, and held at $+20 \mathrm{mV}$. Traces were filtered off-line at $100 \mathrm{~Hz}$. (b) Frequency histogram of observed Nheinduced channel conductance in bilayers bathed in $0.1 \mathrm{M} \mathrm{NaCl}$ with $5 \mathrm{mM}$ HEPES, $\mathrm{pH}$ 7.0. The results are from a total of 171 single-channel events. The channel sizes were Channel conductance (100 pS bins)

of the extent of membrane permeability was obtained by measuring the release of the high-molecular-mass LDH $(140 \mathrm{kDa})$ from Caco-2 monolayers into the bathing solution. Fig. 5(b) shows that $88 \%$ of total cell monolayer $\mathrm{LDH}$ was released at $60 \mathrm{~min}$ after exposure to NVH 0075/ 95 supernatant, whereas $\triangle n h e B C$ supernatant again failed to induce any loss of $\mathrm{LDH}$. Similar release of $\mathrm{LDH}$ was observed in Vero cell monolayers exposed to supernatant from NVH 0075/95 but not in those exposed to supernatant from the $n h e B C$ mutant. $\mathrm{LDH}$ release indicates either complete breakdown of the membrane or the formation of large pores. In the latter case, $\mathrm{LDH}$ release should be delayed or prevented by osmotic protectants. To test this we used PEG of varying molecular size as an osmotic protectant of LDH release in Vero cells. Fig. 5(c) shows the delay in $\mathrm{LDH}$ release induced by the presence of the largest diameter osmotic protectant, PEG 8000 (approximate diameter $7-8 \mathrm{~nm}$ ). The time taken to reach $50 \%$ release of $\mathrm{LDH}$ increased from $13 \mathrm{~min}$ (control) to
$28 \mathrm{~min}$ in the presence of PEG 8000 . LDH release in the presence of additional glucose (0.9 nm diameter), PEG 400 $(1.2-1.4 \mathrm{~nm})$ and PEG $1000(1.8-2.2 \mathrm{~nm})$ was indistinguishable from that of cells without added osmotic protectant.

\section{Nhe increases epithelial cell size prior to cell death}

Using flow cytometry, changes in cell size can be ascertained by measuring forward light scatter as a measure of cell diameter. In Vero cell suspensions the mean cell size increased upon exposure to culture supernatants of $\mathrm{NVH}$ $0075 / 95$, with concomitant (and progressive) uptake of PI (Fig. 6). The changes in cell size were significantly greater than those observed in cells exposed to supernatant from the $\triangle n h e B C$ strain, which did not take up PI (i.e. remained intact). Addition of $\mathrm{mAb} 1 \mathrm{E} 11$ to the culture supernatant prior to addition to the cells abolished both the increase in 
(a)

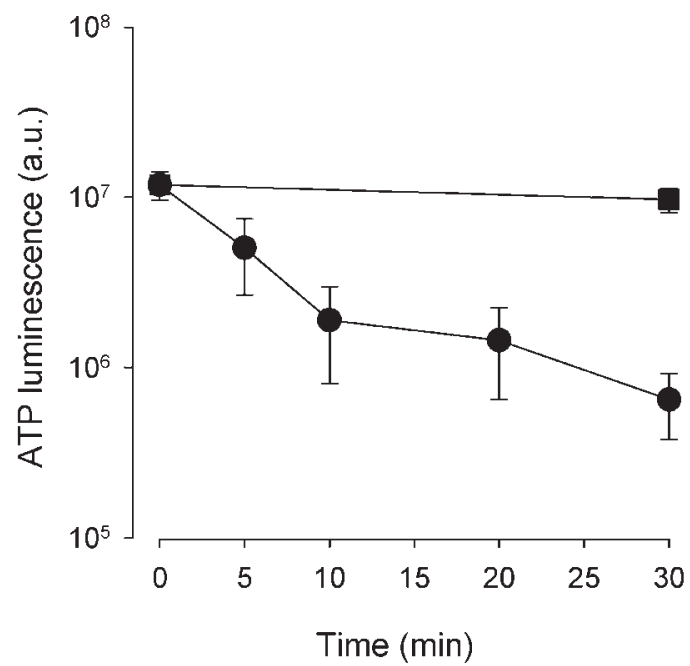

(b)

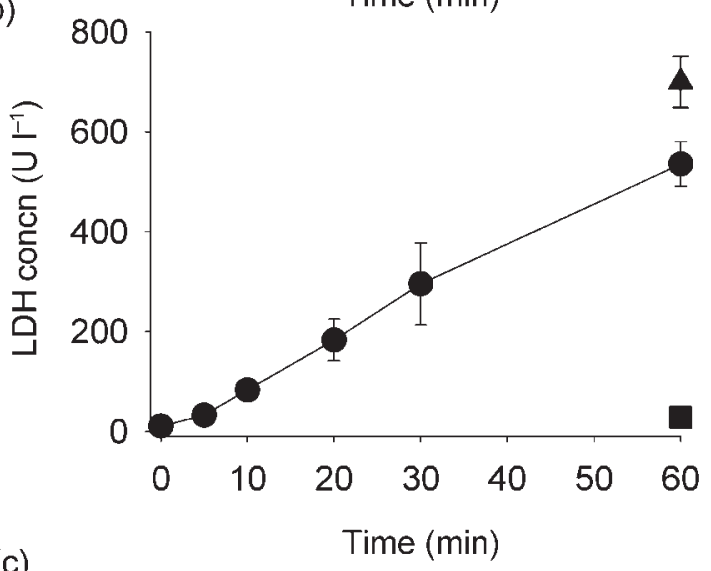

(c)

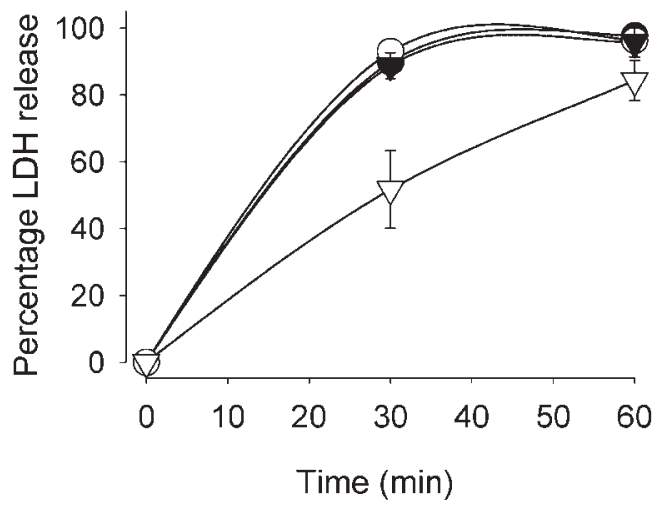

cell size and PI uptake, such that the changes in forward scatter overlaid those observed in the cells exposed to the nheBC mutant.

\section{Homology models of Nhe based on the Hbl B structural template}

The three $\mathrm{Hbl}$ components $\mathrm{L}_{2}, \mathrm{~L}_{1}$ and $\mathrm{B}$ are homologous in sequence to the components of Nhe, which implies that all six $\mathrm{Hbl}$ and Nhe proteins are members of the same protein family (Fig. 7, Table 1). Recently, the crystal structure of $\mathrm{Hbl}$ component $\mathrm{B}$ at $2 \AA(0.2 \mathrm{~nm})$ resolution was deposited in the Protein Data Bank (PDB; www.pdb.org) (PDB ID: 2nrj;
Fig. 5. Epithelial loss of ATP and LDH induced by Nhe. (a) The time-course of total ATP content of Caco-2 epithelial monolayers was monitored after exposure to NVH 0075/95 supernatant (0) and $\triangle n h e B C$ supernatant $(\boldsymbol{\square})$. Values represent mean $\pm \mathrm{SE}, n=3$, for each data point. At time zero the total cellular ATP concentration was approximately $10 \mu \mathrm{M}$ as judged against a standard solution of ATP. The final concentration of cellular ATP at 30 min for the cells treated with NVH 0075/95 supernatant was approximately $0.2 \mu \mathrm{M}$. (b) Extracellular LDH was measured over time following exposure to $\mathrm{NVH} 0075 / 95$ (@) and $\triangle$ nheBC supernatants ( $\boldsymbol{\square})$. Maximum release of LDH from the monolayers induced by $1 \%(\mathrm{v} / \mathrm{v})$ Triton $\mathrm{X}-100$ is indicated by $(\boldsymbol{A})$. Values are mean $\pm \mathrm{SE}, n=3$. (c) Effect of PEG compounds on $\mathrm{LDH}$ release in Vero cell monolayers. LDH release induced by $\mathrm{NVH} \mathrm{0075/95}$ supernatant was monitored in the presence of glucose, PEG 400, PEG 1000 and PEG $8000(\nabla)$. Traces for all compounds except PEG 8000 overlaid each other and were indistinguishable from results obtained with the bathing solution without added osmotic protectant. Values shown are mean $\pm \mathrm{SE}, n=3$.

Fig. 8a). NheB, NheC and $\mathrm{Hbl}_{1}$ showed sufficient sequence similarities to $\mathrm{Hbl} \mathrm{B}$ for generation of 3D homology models using the $\mathrm{Hbl} \mathrm{B}$ structure as the template. The homology models of NheB and NheC created using SWISS-MODEL (Schwede et al., 2003; swissmodel.expasy.org) are shown in Fig. 8(b, c). The 3D structures are predominantly $\alpha$-helical, containing four-helix bundles that wrap around each other in left-handed supercoils, associated with a shorter fifth carboxy-terminal helix. A subdomain consisting of a $\beta$ hairpin flanked by two short $\alpha$-helices is located between the third and fourth helices of the main bundle folded up against the side of the larger domain. $\mathrm{Hbl} \mathrm{B}, \mathrm{NheB}$ and NheC all contain a predicted hydrophobic segment that correlates perfectly with the $\beta$-hairpin.

\section{Nhe and Hbl show structural similarity to ClyA}

A search of the PDB using the VAST structural comparison algorithm (Gibrat et al., 1996) revealed $\mathrm{Hbl} \mathrm{B}$ to be structurally similar to a $34 \mathrm{kDa}$ pore-forming haemolysin from E. coli named cytolysin A (ClyA) (Fig. 8d). (Wallace et al., 2000). Hbl B aligns to ClyA with a VAST structuresimilarity score of 8.9 and a DaliLite (Holm \& Park, 2000) Zscore of 13.8. The two proteins can be superimposed (Fig. 8e) with a root mean square deviation of $4.0 \AA(0.4 \mathrm{~nm})$ for 242 $\mathrm{C} \alpha$ residues, while the crystal structures of $\mathrm{Hbl} \mathrm{B}$ and ClyA contain 331 and 301 residues, respectively. The subdomain containing the $\beta$-hairpin appears to have a different orientation in ClyA compared to $\mathrm{Hbl} \mathrm{B}$, as if tilted out in a more extended conformation. Although an alignment showed only weak similarity between the amino acid sequences of $\mathrm{Hbl} \mathrm{B}$ and ClyA (Table 1, Fig. 7), they share strong structural similarities and several conserved residues.

\section{Haemolytic activity of Nhe}

In the light of the predicted structural and haemolytic activity of $\mathrm{Hbl}$ and ClyA we examined the activity of Nhe 


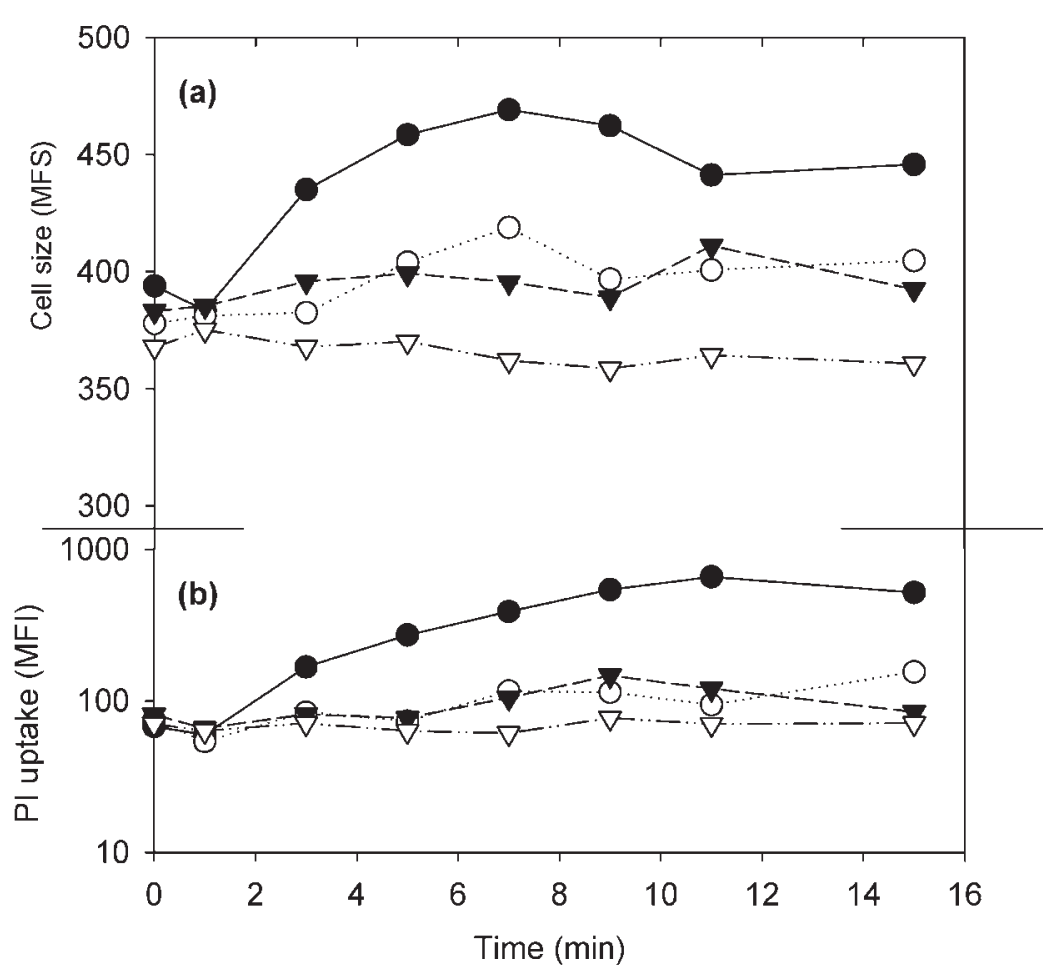

Fig. 6. Vero cell suspensions swell and die upon exposure to NVH 0075/95 culture supernatants. (a) Flow cytometric analysis of Vero cells showing increase in cell size as determined by mean forward scatter (MFS) value after exposure to $20 \mu \mathrm{ml}^{-1} \mathrm{NVH} \mathrm{0075/}$ 95 supernatant $(\bullet)$, which was abolished by preincubation of the toxin with $10 \mu \mathrm{g} \mathrm{mAb}$ $1 \mathrm{E} 11 \mathrm{ml}^{-1}$ for $15 \mathrm{~min}$ on ice $(\bigcirc)$. The response to $\mathrm{NVH}$ 0075/95 culture supernatants was significantly greater than that seen with $20 \mu \mathrm{ml}^{-1}$ supernatant from the nheBC mutant $(\boldsymbol{\nabla}, P<0.05)$. Cells exposed to $E C$ buffer alone are shown as $(\nabla)$. (b) Increase in PI uptake in Vero cells, expressed as mean fluorescence intensity (MFI) of cells per time point. Data were measured simultaneously with forward scatter shown in (a). Only cells exposed to $20 \mu \mathrm{ml}^{-1} \mathrm{NVH} \mathrm{0075/95}$ culture supernatants demonstrated PI uptake alongside cell swelling. The symbols are the same as in (a). Each data point represents $10^{4}$ cells and the figures are representative of two to four experiments for each condition. towards erythrocytes. Incubation of purified Nhe proteins with $1.5 \%$ human erythrocytes at $37{ }^{\circ} \mathrm{C}$ for $1 \mathrm{~h}$ resulted in dose-dependent haemolysis, as determined by haemoglobin release measured at $540 \mathrm{~nm}$ (Fig. 9a). This activity was inhibited when the Nhe components were premixed with the 1 E11 antibody before testing (data not shown). The haemolytic activity of Nhe varied between species, as shown in Fig. 9(b).

\section{DISCUSSION}

The use of an isogenic mutant demonstrates that Nhe has both cytolytic and haemolytic activity, rapidly inducing disruption of epithelial plasma membranes as assayed by four markers of membrane integrity, namely PI uptake, ATP and LDH release from epithelia, and haemoglobin release from erythrocytes. Single channel formation in lipid bilayers and inhibition of lysis of epithelial cells by osmotic protectants strongly indicate that Nhe disrupts epithelial plasma membranes through the insertion of transmembrane pores. This results in colloid osmotic lysis, as indicated by observations of increases in cell size following exposure to Nhe, as measured by forward light scatter.

The use of an $n h e B C$ mutant in B. cereus is dependent on the fact that the strain used, NVH 0075/95, lacks genes encoding the other two dominant cytotoxic components, $\mathrm{Hbl}$ and CytK. The total loss of cytotoxicity in the nheBC mutant reveals the contribution of Nhe to cytotoxicity in culture supernatants. The nheBC mutant producing just the NheA component was employed as we have been unable to create a mutant with deletion of the entire nhe operon, as was also observed by Ramarao \& Lereclus (2006).

The use of unpurified supernatants obviously needs to be judged cautiously, since $B$. cereus is known to produce a variety of additional exotoxins. However, they did not appear to have any primary ability to cause PI uptake, ATP loss or LDH release, since up to $50 \mu \mathrm{lml}^{-1}$ of supernatant from the $\triangle n h e B C$ strain had no demonstrable effect. Furthermore, the antibody neutralization effects strongly indicate that the formation of Nhe-specific pores is the cytotoxic determinant in NVH 0075/95 culture supernatants. Thus, it remains likely that the membrane damage is dependent on the activity of the three Nhe proteins and a cytotoxic contribution from other compounds need not be evoked.

The rapid time-course is consistent with direct pore formation rather than activation of inflammasomemediated death pores. Cells undergoing caspase-dependent cell death resulting from salmonella infection permit influx of fluorescent dyes of up to $1 \mathrm{kDa}$, including propidium, a process that can be blocked by glycine. However this phenomenon is detectable in macrophages after hours rather than minutes (Fink \& Cookson, 2006). More rapid is the membrane permeability to propidium dyes induced by ATP and the marine toxin maitotoxin (Estacion et al., 2003). However, the former appears to use pannexin-1 hemichannel pores triggered by ATP-gated $\mathrm{P}_{2} \mathrm{X}_{7}$ receptors (Pelegrin \& Surprenant, 2006). We have excluded any dependence on exogenous ATP in our system as $300 \mathrm{mM}$ ATP failed to induce PI uptake. The dye permeability induced by maitotoxin can be blocked by glycine, but 


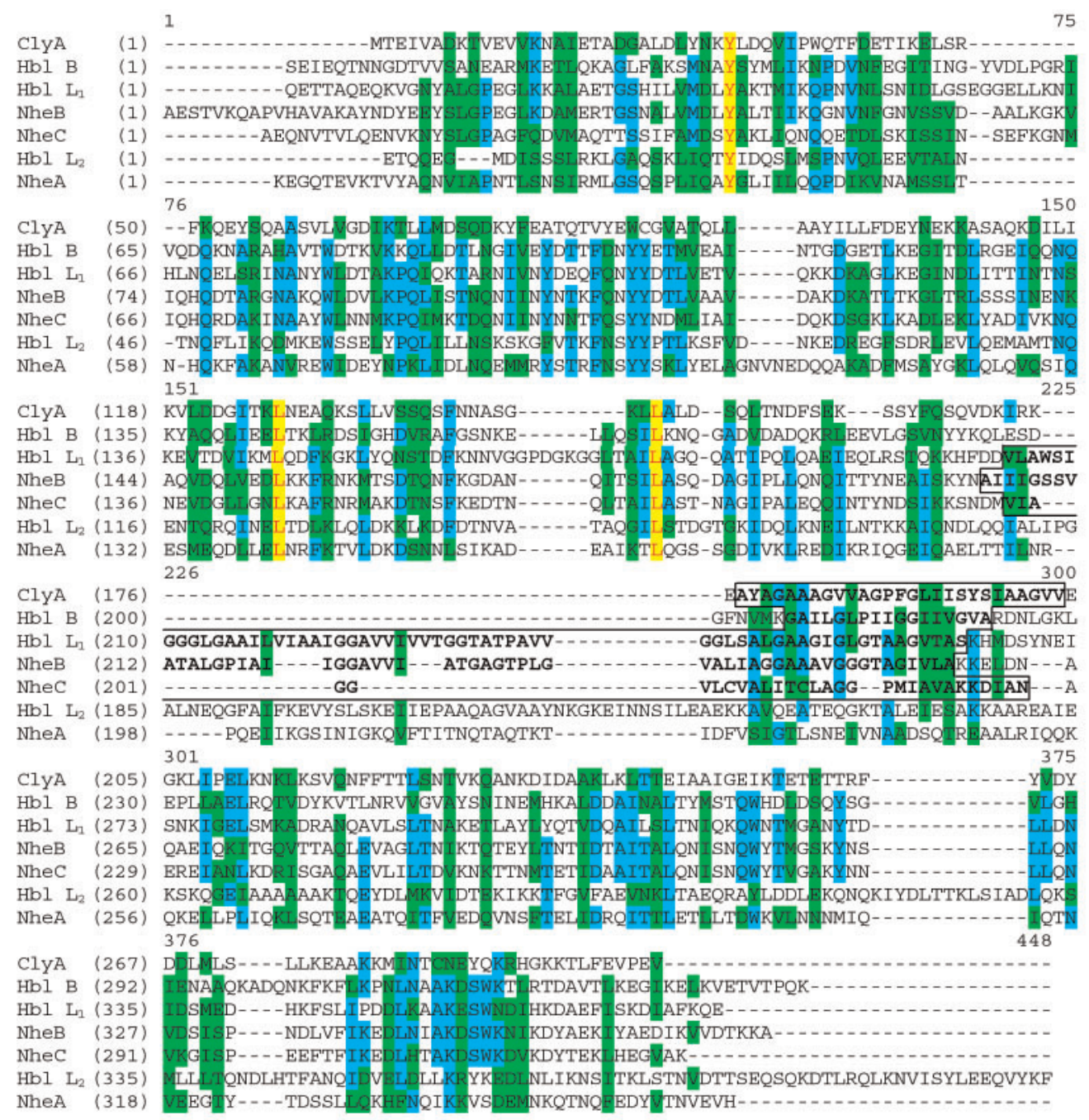

Fig. 7. Multiple sequence alignment of ClyA from E. coli K-12 and the mature sequences of the Hbl and Nhe components from B. cereus ATCC 14579, created using CLUSTAL W. Hydrophobic regions are boxed and in bold type, identical residues are indicated in red type on a yellow background, while blocks of identical and similar residues are indicated by blue and green backgrounds, respectively.

similar inhibition of the Nhe pore was not observed. Thus, whilst we have not measured the caspase dependence of $B$. cereus culture supernatants, and the relationship between pannexin-1 pores and the inflammasome is far from straightforward (Pelegrin \& Surprenant, 2007), we believe that the results can be explained without reference to pannexin-1 channels, pyroptosis and the undefined endogenous death pore blocked by glycine.

Given the complex geometry of endogenous eukaryotic ion channels there is no simple relationship between the electrical conductance in a planar lipid bilayer and the diameter of a transmembrane pore. Nevertheless, to help assess the size of the channels formed by Nhe (200-700 pS in $0.1 \mathrm{M} \mathrm{NaCl}$ ) we note that the conductances of the other pore-forming toxins of B. cereus, CytK and Haemolysin II, are both $600 \mathrm{pS}$, although obtained in 10-fold higher concentrations of ions, i.e. $1 \mathrm{M} \mathrm{NaCl}$ and $\mathrm{KCl}$ (Hardy et al., 2001a; Miles et al., 2002). These toxins form pores by generating transmembrane $\beta$-barrels (Parker \& Feil, 2005), and the archetypal $\beta$-barrel pore former of this group, Staphylococcus aureus $\alpha$-haemolysin, has a diameter of $2.8 \mathrm{~nm}$ at the pore entrance narrowing to $1.4 \mathrm{~nm}$ (Song et al., 1996). Thus, based on conductance values alone we expect the pore formed by Nhe to be substantially larger than this. The release of the high-molecular-mass LDH $(140 \mathrm{kDa})$ is likely to be the result of cell lysis subsequent to pore formation and osmotic swelling. If so, then the delay in LDH release caused by PEG 8000 will be due to blocking of the preceding ionic fluxes through the Nhe pore.

Cytolysin A (ClyA), also known as HlyE and SheA, is a $34 \mathrm{kDa}$ protein that was initially identified in E. coli K-12 


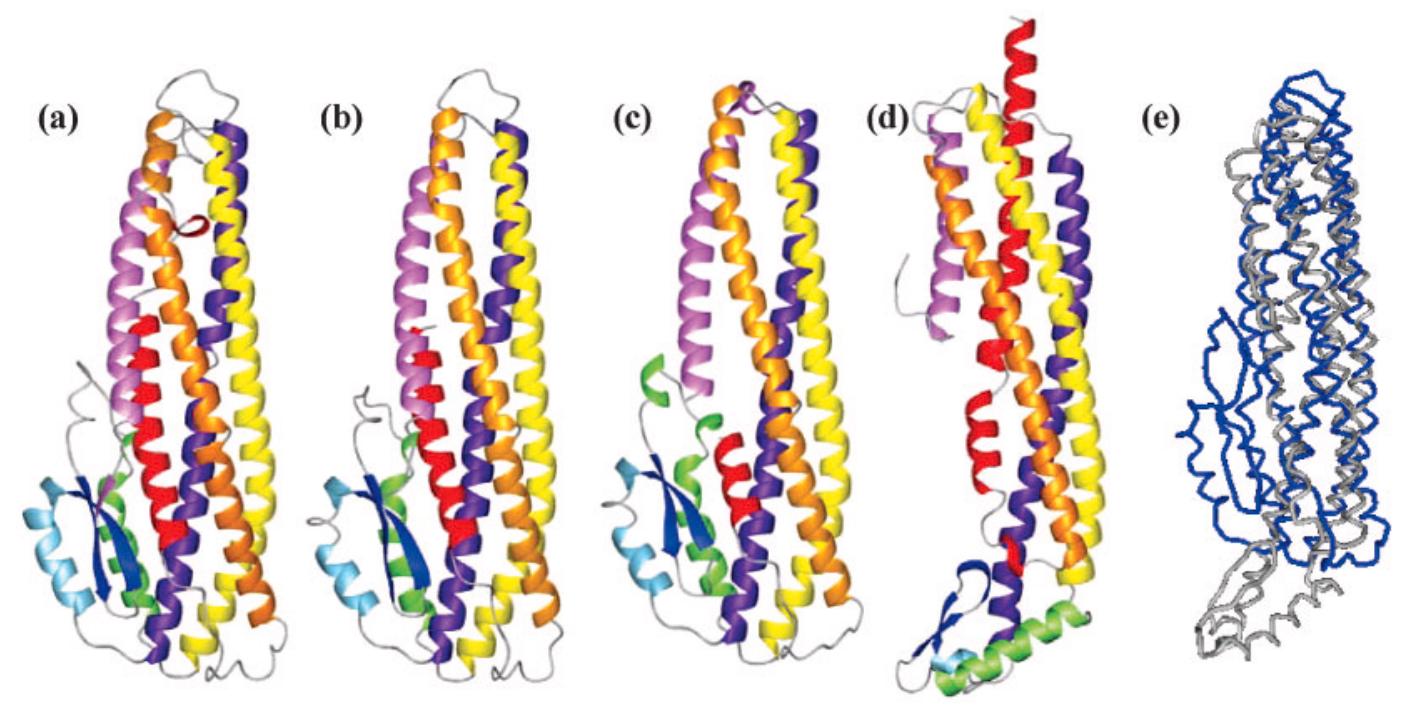

Fig. 8. Structural comparison of $\mathrm{Hbl}$, Nhe and ClyA. (a) Structure of $\mathrm{Hbl}$ component $\mathrm{B}$ as determined by X-ray crystallography (PDB ID: 2nrj). (b) Homology model of NheB. (c) Homology model of NheC. The models in (b) and (c) were created on the basis of the $\mathrm{Hbl} \mathrm{B}$ crystal structure. The first 29 and 34 residues of the mature sequences of NheB and NheC, respectively, and the last 26 residues of NheB were not present in the models obtained. (d) Crystal structure of E. coli ClyA (PDB ID: 1 qoy). Protein structures in $(a-d)$ are shown in ribbon format, with the $\beta$-hairpins in blue, and drawn using MOLMOL (Koradi et al., 1996). (e) Structural alignment visualized as a 3D superimposition of $\mathrm{Hbl} \mathrm{B}$ (blue) and ClyA (grey) obtained using DaliLite, viewed as a $\mathrm{C} \alpha$-trace.

as a haemolysin expressed during anaerobic growth (Green \& Baldwin, 1997; Ludwig et al., 1999; Oscarsson et al., 1996). It is also present in enteropathogenic E. coli (Ludwig et al., 2004), Shigella flexneri (Wallace et al., 2000) and Salmonella enterica serovars Typhi and Paratyphi A (Oscarsson et al., 2002). ClyA is haemolytic and causes LDH release in nucleated cells (delCastillo et al., 1997; Oscarsson et al., 1996, 1999), which has led to the suggestion that it too mediates osmotic lysis through the formation of transmembrane homo-oligomeric pores (Eifler et al., 2006; Tzokov et al., 2006; Wallace et al., 2000). The narrowest pore diameter for ClyA has been measured in cryoelectron microscope images at $4 \mathrm{~nm}$. This is significantly larger than the diameter for the $\beta$-barrel pore-forming toxins (see above) and consistent with the large conductance pores created by Nhe.

The available 3D crystal structure of $\mathrm{Hbl}$ component $\mathrm{B}$ showed tertiary structure resemblance to ClyA of E. coli (Wallace et al., 2000) in a near-global structural alignment, despite limited sequence similarity. Although four-helix bundles like those found in ClyA and $\mathrm{Hbl} \mathrm{B}$ are quite common architectural features of proteins, the subdomain containing the hydrophobic $\beta$-hairpin represents a unique fold (Wallace et al., 2000). The different orientation of this subdomain in the two crystal structures (Fig. 8e) potentially represents crystallization in different conformations, reflecting alternative means of burying the hydrophobic $\beta$-hairpin from the solvent which, in ClyA, is achieved by forming homodimers. 3D crystal structures have not been determined for any of the Nhe proteins, but, judging by sequence homology, they are likely to adopt a fold similar to that of $\mathrm{Hbl} \mathrm{B}$, as structural similarities are usually highly conserved during protein evolution.

In addition to the common key structural features there are also clear functional correlates between $\mathrm{Hbl}$, Nhe and ClyA: they are all bacterial pore-forming toxins with cytolytic and haemolytic activity. The pores formed by Nhe and ClyA are both weakly cation-selective in lipid bilayer experiments, and the pore conductances, 200-700 pS in $0.1 \mathrm{M} \mathrm{NaCl}$ for Nhe and $1000 \mathrm{pS}$ in $0.1 \mathrm{M} \mathrm{KCl}$ for ClyA (Ludwig et al., 1999), are broadly comparable, given that potassium ions have greater ionic mobility than sodium. Comparisons between the pore sizes of ClyA and Nhe remain only very tentative, since Nhe requires three separate proteins for maximum cytotoxicity, whereas ClyA is a homooligomer, and we present no data to identify the extent to which Nhe needs to oligomerize in this process.

Structural comparison methods such as VAST and DaliLite used in the current study can detect evolutionary relationships that are not apparent when judged by sequence similarities alone (Gibrat et al., 1996). However, such methods may not always distinguish between remote homologues linked by divergent evolution, and analogous proteins obtained through parallel evolution, especially when only very limited sequence similarity is present. In such cases, determination of homology and classification into superfamilies is performed on combined sequence, structural and functional information, since divergent evolution from a common ancestor retains not only similar folding but also functional features (Dietmann \& 

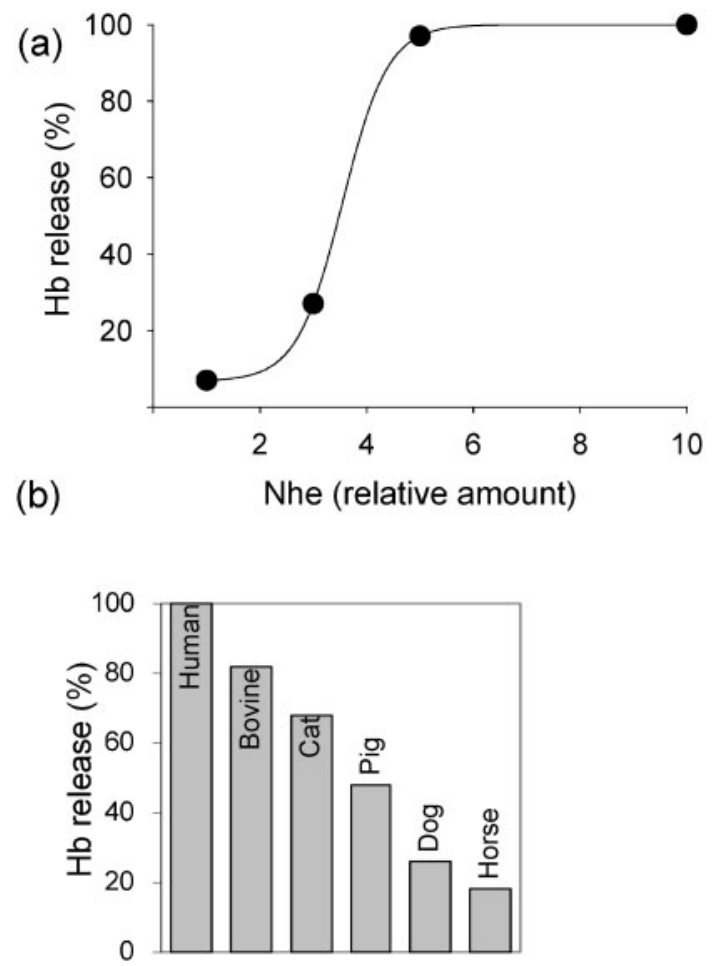

Fig. 9. Haemolytic activity of purified Nhe proteins. (a) Haemolytic dose-response curve of purified Nhe proteins incubated with $1.5 \%$ human erythrocytes. Purified Nhe proteins were used at a ratio of $6: 6: 1$ NheA:NheB:NheC, using approximately $100 \mathrm{ng}$ NheA $\mathrm{ml}^{-1}$ and expressed relative to this. (b) Species differences in sensitivity of erythrocytes to Nhe. Suspensions were adjusted to an $\mathrm{OD}_{630}$ equal to that of $1.5 \%$ human blood. The amount of Nhe used corresponds to the highest concentration used in (a). The percentage of the maximal release of haemoglobin $(\mathrm{Hb})$ was calculated relative to $100 \%$ lysis of controls consisting of the same type of erythrocytes. Data represent the mean of two to five experiments for each species.

Holm, 2001). Thus, the strongest argument for homology between the ClyA and the Hbl/Nhe families of toxins stems from the association of similar unique structures with a common functional property, the formation of transmembrane pores in eukaryotic cell membranes.

In summary, through the use of a deletion mutant and purified proteins we have identified a mechanism of cytotoxicity for Nhe, namely osmotic lysis following pore formation in the plasma membrane. We propose that the structural and functional similarities among Nhe, $\mathrm{Hbl}$ and ClyA indicate that they constitute a superfamily of poreforming toxins.

\section{ACKNOWLEDGEMENTS}

We are indebted to Kristin O'Sullivan for the endless hours spent purifying Nhe. The authors also thank Richard Dietrich and Erwin Märtlbauer (Ludwig-Maximilians-Universität, Munich) for the generous supply of monoclonal antibodies, and Erik Ropstad (Norwegian School of Veterinary Science, Oslo) for the use of the Wallac Victor ${ }^{3}$. A.F. was supported by the Research Council of Norway (164805/I10).

\section{REFERENCES}

Arnaud, M., Chastanet, A. \& Débarbouillé, M. (2004). New vector for efficient allelic replacement in naturally nontransformable, lowGC-content, Gram-positive bacteria. Appl Environ Microbiol 70, 6887-6891.

Beecher, D. J. \& Macmillan, J. D. (1991). Characterization of the components of hemolysin-BL from Bacillus cereus. Infect Immun 59, 1778-1784.

del Castillo, F. J., Leal, S. C., Moreno, F. \& del Castillo, I. (1997). The Escherichia coli K-12 sheA gene encodes a $34-\mathrm{kDa}$ secreted haemolysin. Mol Microbiol 25, 107-115.

Dietmann, S. \& Holm, L. (2001). Identification of homology in protein structure classification. Nat Struct Biol 8, 953-957.

Dietrich, R., Fella, C., Strich, S. \& Märtlbauer, E. (1999). Production and characterization of monoclonal antibodies against the hemolysin BL enterotoxin complex produced by Bacillus cereus. Appl Environ Microbiol 65, 4470-4474.

Dietrich, R., Moravek, M., Burk, C., Granum, P. E. \& Märtlbauer, E. (2005). Production and characterization of antibodies against each of the three subunits of the Bacillus cereus nonhemolytic enterotoxin complex. Appl Environ Microbiol 71, 8214-8220.

Ehling-Schulz, M., Svensson, B., Guinebretiere, M. H., Lindbäck, T., Andersson, M., Schulz, A., Fricker, M., Christiansson, A., Granum, P. E. \& other authors (2005). Emetic toxin formation of Bacillus cereus is restricted to a single evolutionary lineage of closely related strains. Microbiology 151, 183-197.

Eifler, N., Vetsch, M., Gregorini, M., Ringler, P., Chami, M., Philippsen, A., Fritz, A., Müller, S. A., Glockshuber, R. \& other authors (2006). Cytotoxin ClyA from Escherichia coli assembles to a 13-meric pore independent of its redox-state. EMBO J 25, 2652-2661.

Estacion, M., Weinberg, J. S., Sinkins, W. G. \& Schilling, W. P. (2003). Blockade of maitotoxin-induced endothelial cell lysis by glycine and L-alanine. Am J Physiol Cell Physiol 284, C1006-C1020.

Fink, S. L. \& Cookson, B. T. (2006). Caspase-1-dependent pore formation during pyroptosis leads to osmotic lysis of infected host macrophages. Cell Microbiol 8, 1812-1825.

Gibbons, S. J., Washburn, K. B. \& Talamo, B. R. (2001). P2X receptors in rat parotid acinar cells: formation of large pores. J Auton Pharmacol 21, 181-190.

Gibrat, J. F., Madej, T. \& Bryant, S. H. (1996). Surprising similarities in structure comparison. Curr Opin Struct Biol 6, 377-385.

Granum, P. E., O’Sullivan, K. \& Lund, T. (1999). The sequence of the non-haemolytic enterotoxin operon from Bacillus cereus. FEMS Microbiol Lett 177, 225-229.

Green, J. \& Baldwin, M. L. (1997). The molecular basis for the differential regulation of the hlyE-encoded haemolysin of Escherichia coli by FNR and HlyX lies in the improved Activating Region 1 contact of HlyX. Microbiology 143, 3785-3793.

Guérout-Fleury, A. M., Shazand, K., Frandsen, N. \& Stragier, P. (1995). Antibiotic-resistance cassettes for Bacillus subtilis. Gene 167, 335-336.

Hardy, S. P., Lund, T. \& Granum, P. E. (2001a). CytK toxin of Bacillus cereus forms pores in planar lipid bilayers and is cytotoxic to intestinal epithelia. FEMS Microbiol Lett 197, 47-51. 
Hardy, S. P., Ritchie, C., Allen, M. C., Ashley, R. H. \& Granum, P. E. (2001b). Clostridium perfringens type A enterotoxin forms mepacrinesensitive pores in pure phospholipid bilayers in the absence of putative receptor proteins. Biochim Biophys Acta 1515, 38-43.

Hauge, S. (1955). Food poisoning caused by aerobic spore-forming bacilli. J Appl Bacteriol 18, 591-595.

Holm, L. \& Park, J. (2000). DaliLite workbench for protein structure comparison. Bioinformatics 16, 566-567.

Koradi, R., Billeter, M. \& Wuthrich, K. (1996). MOLMOL: a program for display and analysis of macromolecular structures. J Mol Graph 14, 51-55.

Lindbäck, T. \& Granum, P. E. (2006). Detection and purification of Bacillus cereus enterotoxins. In Methods in Biotechnology, Volume 21: Food-borne pathogens: Methods and protocols, pp. 15-26. Edited by C. C. Adley. Totowa, NJ: Humana Press.

Lindbäck, T., Fagerlund, A., Rødland, M. S. \& Granum, P. E. (2004). Characterization of the Bacillus cereus Nhe enterotoxin. Microbiology 150, 3959-3967.

Ludwig, A., Bauer, S., Benz, R., Bergmann, B. \& Goebel, W. (1999). Analysis of the SlyA-controlled expression, subcellular localization and pore-forming activity of a $34 \mathrm{kDa}$ haemolysin (ClyA) from Escherichia coli K-12. Mol Microbiol 31, 557-567.

Ludwig, A., von Rhein, C., Bauer, S., Huttinger, C. \& Goebel, W. (2004). Molecular analysis of cytolysin A (ClyA) in pathogenic Escherichia coli strains. J Bacteriol 186, 5311-5320.

Lund, T. \& Granum, P. E. (1996). Characterisation of a nonhaemolytic enterotoxin complex from Bacillus cereus isolated after a foodborne outbreak. FEMS Microbiol Lett 141, 151-156.

Lund, T. \& Granum, P. E. (1997). Comparison of biological effect of the two different enterotoxin complexes isolated from three different strains of Bacillus cereus. Microbiology 143, 3329-3336.

Lund, T., De Buyser, M. L. \& Granum, P. E. (2000). A new cytotoxin from Bacillus cereus that may cause necrotic enteritis. Mol Microbiol 38, 254-261.

Masson, L., Prefontaine, G. \& Brousseau, R. (1989). Transformation of Bacillus thuringiensis vegetative cells by electroporation. FEMS Microbiol Lett 60, 273-278.

Miles, G., Bayley, H. \& Cheley, S. (2002). Properties of Bacillus cereus hemolysin II: a heptameric transmembrane pore. Protein Sci 11, 1813-1824.

Moravek, M., Dietrich, R., Buerk, C., Broussolle, V., Guinebretiere, M. H., Granum, P. E., Nguyen-The, C. \& Märtlbauer, E. (2006). Determination of the toxic potential of Bacillus cereus isolates by quantitative enterotoxin analyses. FEMS Microbiol Lett 257, 293-298.

Oscarsson, J., Mizunoe, Y., Uhlin, B. E. \& Haydon, D. J. (1996). Induction of haemolytic activity in Escherichia coli by the slyA gene product. Mol Microbiol 20, 191-199.

Oscarsson, J., Mizunoe, Y., Li, L., Lai, X. H., Wieslander, A. \& Uhlin, B. E. (1999). Molecular analysis of the cytolytic protein ClyA (SheA) from Escherichia coli. Mol Microbiol 32, 1226-1238.
Oscarsson, J., Westermark, M., Löfdahl, S., Olsen, B., Palmgren, H., Mizunoe, Y., Wai, S. N. \& Uhlin, B. E. (2002). Characterization of a pore-forming cytotoxin expressed by Salmonella enterica serovars Typhi and Paratyphi A. Infect Immun 70, 5759-5769.

Ouhib, O., Clavel, T. \& Schmitt, P. (2006). The production of Bacillus cereus enterotoxins is influenced by carbohydrate and growth rate. Curr Microbiol 53, 222-226.

Parker, M. W. \& Feil, S. C. (2005). Pore-forming protein toxins: from structure to function. Prog Biophys Mol Biol 88, 91-142.

Pelegrin, P. \& Surprenant, A. (2006). Pannexin-1 mediates large pore formation and interleukin- $1 \beta$ release by the ATP-gated $\mathrm{P}_{2} \mathrm{X}_{7}$ receptor. EMBO J 25, 5071-5082.

Pelegrin, P. \& Surprenant, A. (2007). Pannexin-1 couples to maitotoxin- and nigericin-induced interleukin- $1 \beta$ release through a dye uptake-independent pathway. J Biol Chem 282, 2386-2394.

Planchot, V., Roger, P. \& Colonna, P. (2000). Suitability of starch granule porosity for biosynthesis and amylolysis susceptibility. Starch 52, 333-339.

Ramarao, N. \& Lereclus, D. (2006). Adhesion and cytotoxicity of Bacillus cereus and Bacillus thuringiensis to epithelial cells are FlhA and PlcR dependent, respectively. Microbes Infect 8, 1483-1491.

Ryan, P. A., Macmillan, J. D. \& Zilinskas, B. A. (1997). Molecular cloning and characterization of the genes encoding the $\mathrm{L}_{1}$ and $\mathrm{L}_{2}$ components of hemolysin BL from Bacillus cereus. J Bacteriol 179, 2551-2556.

Scherrer, R. \& Gerhardt, P. (1971). Molecular sieving by Bacillus megaterium cell wall and protoplast. J Bacteriol 107, 718-735.

Schilling, W. P., Sinkins, W. G. \& Estacion, M. (1999). Maitotoxin activates a nonselective cation channel and a P2Z/P2X $\mathrm{X}_{7}$-like cytolytic pore in human skin fibroblasts. Am J Physiol Cell Physiol 277, C755-C765.

Schoeni, J. L. \& Wong, A. C. L. (2005). Bacillus cereus food poisoning and its toxins. J Food Prot 68, 636-648.

Schwede, T., Kopp, J., Guex, N. \& Peitsch, M. C. (2003). SWISSMODEL: an automated protein homology-modeling server. Nucleic Acids Res 31, 3381-3385.

Song, L., Hobaugh, M. R., Shustak, C., Cheley, S., Bayley, H. \& Gouaux, J. E. (1996). Structure of staphylococcal $\alpha$-hemolysin, a heptameric transmembrane pore. Science 274, 1859-1866.

Tzokov, S. B., Wyborn, N. R., Stillman, T. J., Jamieson, S., Czudnochowski, N., Artymiuk, P. J., Green, J. \& Bullough, P. A. (2006). Structure of the hemolysin E (HlyE, ClyA, and SheA) channel in its membrane-bound form. J Biol Chem 281, 23042-23049.

Wallace, A. J., Stillman, T. J., Atkins, A., Jamieson, S. J., Bullough, P. A., Green, J. \& Artymiuk, P. J. (2000). E. coli hemolysin E (HlyE, ClyA, SheA): X-ray crystal structure of the toxin and observation of membrane pores by electron microscopy. Cell 100, 265-276.

Whitaker, J. R. \& Granum, P. E. (1980). An absolute method for protein determination based on difference in absorbance at 235 and $280 \mathrm{~nm}$. Anal Biochem 109, 156-159.

Edited by: J. Green 